\title{
Study the Responsory And Quantum Efficiency of Silicon P-N Junction by Using Pulse Plasma
}

\author{
1* Salah A. Sheet, ${ }^{2}$ Mohammad N. Abdulwahab
}

Department of Physiology and Physics, College of Medicine, University of Ninevah, Mosul, Iraq

E-mail: ${ }^{1 *}$ Drsalah53@gmail.com,${ }^{2}$ mohammed.abdulwahab@uoninevah.edu.iq

(Received April 08, 2012; Accepted May 08, 2013; Available online December 01, 2020)

DOI: 10.33899/edusj.2020.167287, (C) 2020, College of Education for Pure Science, University of Mosul.

This is an open access article under the CC BY 4.0 license (http://creativecommons.org/licenses/by/4.0/).

\begin{abstract}
In this work we have used plasma pulsed injector to prepare a P-N junction. Antimony was deposited on P-type silicon wafer and Indium was deposited on $\mathrm{N}$-type silicon wafer. They were considered as thin film which was bombarded with accelerated hydrogen-ions from the pulsed plasma injector.

Optical tests were conducted for the both junctions to evaluate their performance as optical detectors. These include the spectral response quantum efficiency and detectivity. They showed high response and efficiency for the long wavelength in the near IR region. It showed a relatively higher detectivity which increased with the number of discharges.

For antimony and indium implanted samples we have noticed an increase in the response time of the detector with the number of discharges. These findings allow the possibility to use them in the near IR-detector and semiconductor lasers in the wavelength range $850-950 \mathrm{~nm}$ as well as in the applications of optical communication systems.

This work also revealed the possibility of using the pulsed plasma injection to modify the material surfaces as well as the ultering the semiconductor surfaces.
\end{abstract}

Keywords: P-N Junction - Pulse Plasma - Irradiation

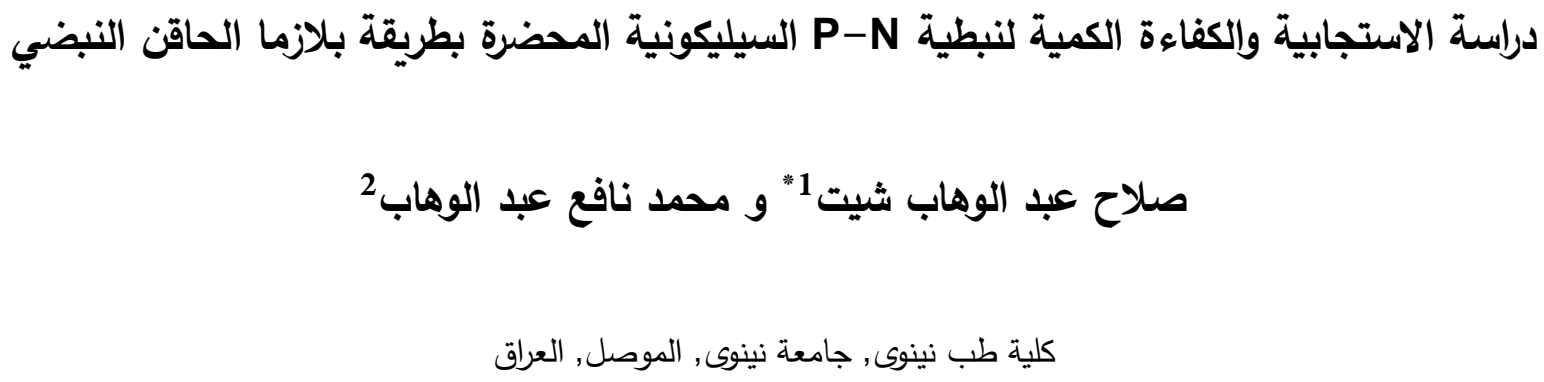

الخلاصة

$$
\begin{aligned}
& \text { استخدمت منظومة حاقن البلازما النبضي لتحضير ثنائي وصلة P-N Junction حيث تم ترسيب مادة الأنتيمون على } \\
& \text { شريحة السيلكون نوع توصيلية P ومادة الانديوم على شريحة السيلكون نوع توصيلة كأغشية رقيقة وقصفت النماذج بأيونات } \\
& \text { الهيدروجين المعجلة والمتولدة في منظومة حاقن البلازما النبضي. } \\
& \text { اجريت الفحوصات البصرية للثنائيات المحضرة لتقييمها ككواشف بصرية والتي شملت فحوصات الاستجابية الطيفية والكفاءة } \\
& \text { الكمية والتحسية وقد أظهرت النتائج بأن هذه الكواشف ذات استجابية وكفاءة كمية أعلى للاطوال الموجية للاشعة تحت الحمراء }
\end{aligned}
$$


القرببة. وقد أظهرت كذلك تحسسية عكسية نسبيا وان الاستجابية والتحسية تزداد بزيادة عدد التفريغات الكهربائية للنماذج المحضرة ولوحظ زيادة في زمن استجابة الكثف بزيادة تعرض النماذج إلى عدد أكبر من التفريغات الكهربائية للنماذج المطعمة بالأنتيمون والانديوم مما يتيح استخدامها في كواشف الاستقبال العاملة في مجال الاشعة تحت الحمراء القريبة وفي منظومات الليزر لاشباه الموصلات العاملة ضمن الاطوال الموجبة (850mm إلى 950nm) وفي منظومات الاتصالات البصرية. وكذلك إمكانية استخدام منظومة حاقن البلازما النبضي في تحوير سطوح المواد وخاصة في مجال تحوير سطوح أثباه الموصلات.

$$
\text { الكلمات المفتاحية: نبطية p-n - الحاقن النبضي - التشعيع }
$$

1-1

في حالة المكائن ذات الجدران المعدنية فان التفريخ يكون مســـاره من القطب الموجب إلى الجدران بحيث يتقوس غلاف التيار في مقدمـة القطب ليكون القرص بـاتجـاه Z وبمـا يمكن من الحصـــول على تركيز عـالي للأيونـات والتي تقدر بحوالي

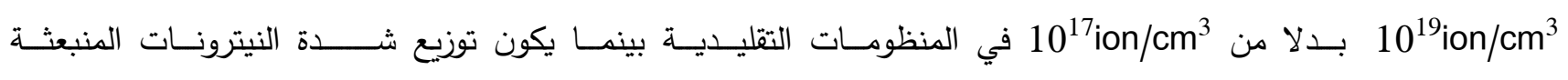
متماثلا تقريبا [2, 1 [م لقد طور العالم Filipov حجيرة القرص باتجاه Z بوجود جدار موصسل في ماكنة التبؤر Focus Machine الثكل (1a) وفي نفس الوقت فان العالم Mather استطاع أن يطور منظومة تبؤر البلازما من منظومة مارسال الثكل (1b) [3].

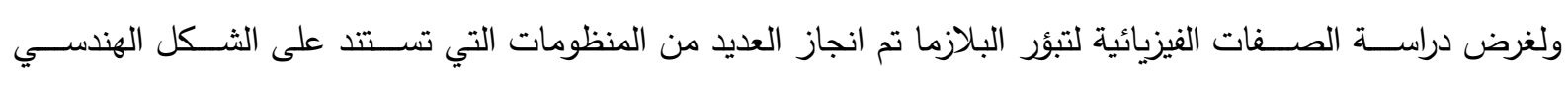
للمنظومتين آنفتي الذكر وبتقيييـات تختلف باختلاف الطاقات المســخدمة بدءا من KJ1 وحتى MJ1 وعند ضـــوط مختلفة لغاز

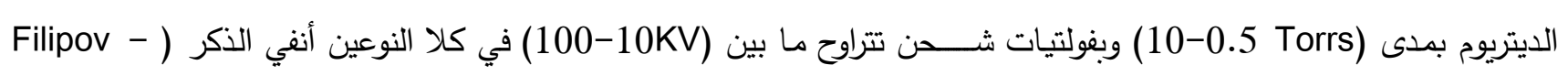
(Mather

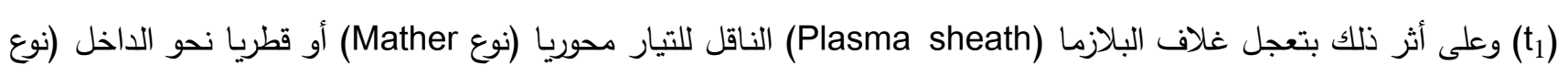
(Filipov

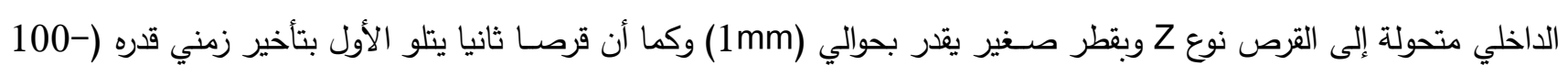
.[4,1] (50ns

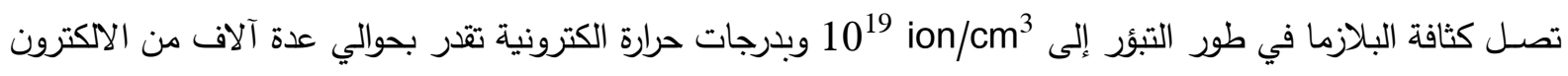
فولت كما يكون هذا التبؤر مصـحوبا بانبعاث نيوترونات وبحصـيلة تصـل إلى 12 $10^{12}$ نيوترون اضــافة إلى انبعاث الأشـعة السـينية

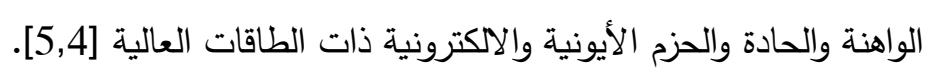
1-2 مكونات حاقن البلازما النبضي: يتكون حاقن البلازمـا النبضـــي Pulse Plasma Injection (PPI) من عدة منظومات ثانويـة وفرعية بتناغم منظم للحصول على الأداء المطلوب وكما في الثكل (3) ومن هذه المنظومات الفرعية: 
1-2-1

وهي عبارة عن اسطوانة معدنية من مادة الفولاذ المقاوم للصدأ مثبت فيها قطبي التفريخ الكهربائي ونوافذ أو أماكن خاصــة لاستخدامها للفحوصات والقياسات وتوصيلات التفريخ الغازي وضخ الغاز . تكون مادة الاقطاب من النحاس وعلى هيئة اسطوانتين متحدتي المركز ويتم تصنيع الاسطوانة الخارجية القطب الخارجي من أعمدة معدنية تحيط بالقطب الداخلي أو الاسطوانة الداخلية. 1 2-2-2 منظومة التفربغ الغازي:

تحتل هذه المنظومة الأهمية الخاصة في منظومة حاقن البلازما النبضي بأنواعها كافة حيث يعتمد الأداء على كفاءة عملية التفريخ والضــخ الغازي والوصـول إلى حدود تفريخ بحدود 10 mbar والتي يمكن الوصـول إليها باسـتخدام مضـخة تفريخ انتشـارية

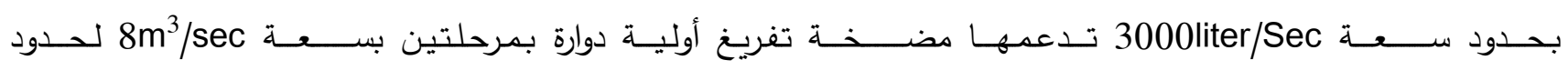
الضغط $10^{-3}$ mbar. يتم قياس الضـــط للحدود الواطئة باســـخدام مقياس التأين الغازي نوع (Pining) وللحدود العالية يتم باســتخدام مقياس المزدوج الحراري نوع (Pirany gage). 3-2-1 يتضح من مخطط منظومة حاقن البلازما النبضي المبين في الثكل (3) من الجزء الأساسي فيها هو مجموعة المتسعات

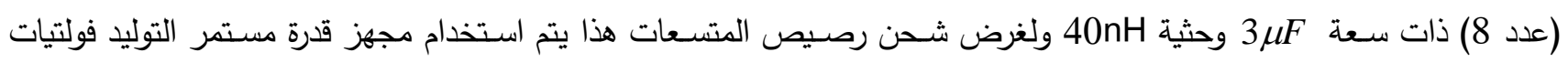
شـن من صـر إلى kv 25 وتيار شـن mA 50 أما الجزء الآخر فهو المفاتيح الكهربائية والتي تكون من نوع فجوة القدح وتكون سريعة وتستطيع تحمل الفولتيات والتيارات العالية وتجهز هذه المفاتيح بنبضـات فولتية تصـل إلى حدود kV 90 حيث تتماشسى مع متطلبات التثريخ وتكون سرعة الاستجابة لتفريخ رصيص المتسعات أقل من Nriggering pulse 20 والتي تمثل اشارة البدء أما نقل الطاقة المخزونـة من رصـــيص المتســــات إلى حجرة التأين فيتم عن طريق 16 ناقل محوري ذو حثية واطئة بحدود 40nH/ ـ و وتتصف منظومة التأريض بكونها ذات مقاومة واطئة بحدود 1 أوم وحثية واطئة بحدود (100nH/Sec). 1 نظرا لتثـعب وتتوع الظواهر الفيزياوية في منظومة حاقن البلازما النبضـي لذلك تتوعت واختلفت طرق التشـخيص والقياس ومنها تسجيل شكل نبضـة التيار ونبضـة الفولتية الغرض وصف ديناميكية البلازما المنتجة ويستخدم ملف راكوفسكي كما في الثكل (4) لقياس التيار أثناء نشوء واضمحلال البلازما ويستخدم مجزئ جهد نبضي عالي ذو حثية واطئة لتسجيل الثكل الموجي للفولتية الخارجة وقد مررت الاثكال الموجية للتيار والفولتية على حاسبة الكترونية عبر اوسـيلوسكوب (Oscilloscopes سـريعة ( 350 (MHz ومن أجهزة التشخيص المهمة أيضـا هي الكاميرة الأيونية الدبوسية (lonic pinhole camera) والتي تستخدم لاغراض القياسات الأيونية وبواسطتها يمكن الحصول على ص ورة مكبرة للانبعاثات الأيونية وبواسطة قدحة تفريغ مفردة أو تفريغات متسلسلة وتركب الكاميرا على حجرة التأين كما في الثكل (5) فإذا ما عرض الفلم البلاستيكي لكواشف الحالة الصلبة ذات المسارات النووية Solid state nuclear track detector (SSNTD) 
لمجموعة التفريغات ويمكن السيطرة على عدد الأيونات التي تصـل إلى الفلم البلاستيكي بتغيير قيمة الضـغط العامل أو المرشحات وغالبا ما تستخدم مرشحات الالمنيوم لحجب الطاقات غير المرغوب فيها.

1-3-1 استعراض الاعمال التجريبية:

بعد التطور الذي حصل في منظومات بؤرة البلازما الكثيفة تركز الاهتمام نحو الاستفادة منها كاحدى المصـادر النيترونية النبضـــية بــــبـ كونها ذات نواتج نيترونية عالية وقد رافق هذا الاهتمام تقييس المنظومات بالاعتماد على النتائج العملية واجراء الحسابات النظرية وبناء البرامج المتعددة لحل المعادلات التي تصف اطوار البلازما بغية الوصول إلى أفضل النتائج في هذا المجال ضمن اعتبارات تصميمية وقياسية معينة.

لقد وضعت قوانين تقييس مختلفة في هذا المجال كدالة لطاقة خزن رصيص المتسعات أو دالة للتيار الاعظم max 1 أو دالة لتيار حجيرة القرص , ففي الوقت الذي وضــــع فيها Rapp قانونا لتقييس المنظومة كدالة لطاقة متســـعات الخزن ووجد Linil و قernard بأن قوانين التقييس التجريبية الموضــــوعة كدالة للتيار الأعظم أو دالة للطاقة المخزونة أو تيار القرص تعطي نتائج محدودة الدقة ولمدى معين من الطاقات والتيارات[9,10,11]. ومن ناحية أخرى أجريت عدة تجارب ودراســات نظرية لتبيان مدى تأثير المعلمات الكهربائية للمنظومة على كفاءة تثغيلها ومنها ما يتعلق باعلومات الدائرة الكهبائية الخارجية وعلى وجه الخصوص الحثية الخارجية، فولتية الادخال، التيار الاعظم للدائرة القصــيرة (Short Circuit) وعلاقتها بتغير المعلمات الكهربائية للبلازما [13,12,6,14,2)

ومنها ما يتعلق باختيار الأمثلية التثغيلية لعدة غازات نقية أو مشوبة وتبيان تأثيرهما على الحصيلة النيترونية [16,15,11,10]. ان استجابة نبضـية (p-n) السيليكونية تكون غير منتظمة لركائز مختلفة وتعتمد على التشعيع بالبروتونات بطاقة ( 10 وقد تم ذلك باستخدام عدة تقنيات مكملة. وقد تم من الدراسة أن التشعيع يؤثر على مميزات التيار -فولتية وكذلك على قياسات عمر الزمن والمعتمدة على درجة الحرارة عن طريق البيانات الكهربائية الناتجة من التحليل الطيفي. [18] تم تعجيل البروتونات والايونات الثقيلة الى سرعة تقرب من سرعة الضوء في الساينكترون، بلغت الطاقة الحركية القصوى دئ

للبروتونات (7 Tev). ان تصادم شعاعين بالاتجاه المقابل قد تم دراسته في مواضع مختلفة من الساينكترون. [19,20] تم جمع جسـيمات جديدة تدعى (البوزونات) عن طريق التجارب (ATLAS) و (CMS) في مكائن التصــادم للهيدرونات

الثقيلة [21].

في كل (25s ) سوف تتصادم حزمتين من البروتونات وسوف ينتج عن ذلك طيف يمثل روؤس اولية بحوادث التصادم،

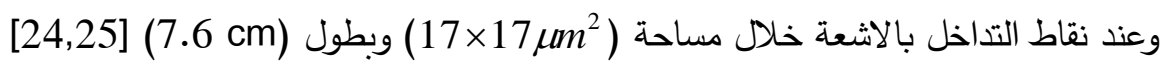
الطبقات الخارجية من المسار تم تصميمها باستخدام قطاعات من مجسات السيليكون التي تحتوي مساحة واسعة لكل قناة

منفردة [24]

تم تجميع مسـعر ذو تقسـيمات عالية في الاتجاه الامامي، في المقطع الكهرومغناطيسـي سـوف تحصـل خاصـية تغيير

الطبقات للمادة الماصة وطبقات السيليكون كمادة مجس فعالة نشطة. [25,26,27,28] تم جمع وتسـجيل التأين الناتج من مرور الجسـيمات المشـحونة خلال حيز معين، تم امرار الكترونات من الفراغ الى عداد [29] (12 to 20 Kev) السيليكون وتم مقارنة قياس اطياف الطاقة الى القيم المتوقعة خلال مدى من الطاقات يتراوح من من مرئ 
تم دراسـة استجابة الجرعة الثـعاعية للعداد وقد تبين ان الاسـتجابة الزاوية الحقيقية قد اظهرت انحراف مقداره (8\%) عند الزاوية (90)، وتم تقليل حساسية الاشعاع بمقدار (25\%) بعد تراكم الجرعة الاشعاعية البالغة (20 kGy) ولكن الحساسية استقرت

بعد ذلك. [30]

تم دراسـة عدة معلمات مثل النسبة الخارجية لعرض شبه الضل، حجم مجال قياس الجرعات والنسبة المئوية للجرعة على السطح في مجالات اشعات مختلفة وتم ذلك باستخدام حجرة التأين ومقياس الجرع الاشعاعية من المواد شبه الموصلة. [31] 1-1

يهدف بحثنا هذا إلى اســخدام شـوائب ثلاثية وخماسـية في عمليات الزرع الايوني النبضــي كالانتيمون والانديوم والتي لم تدرس سابقا في هذا المجال واعتماد اسلوب ترسيبهما كأغشية رقيقة على أرضية السيلكون نوع توصيلة N ,P لتحويلها إلى وصلة ثنائي P Junction أخرى وتم الترسـيب في مختبرات كلية العلوم جامعة بغداد. ثم تم قصـفهما بايونات الهيدروجين المعجلة والمتولدة في منظومة حاقن البلازما النبضـي ولهذا الغرض تتاول البحث الاعتبارات التصــيمية الخاصــة بالمنظومة العاملة مع شـروط الامثلية التثـغيلية لهما دراســــة التوزيع الأيوني المكاني والطاقي للايونات المنبعثة والمتجهة نحو الهدف بغية التعرف على الكثافة الأيونية وحدود الطاقات المستخدمة وامكانيات استخدامه في التطبيقات التقنية. كما يهدف البحث إلى دراسة الخواص البصرية والكهربائية لوصلة الثنائي المحضرة لتحديد إمكانية استخدام هذه التقنية في التطبيقات الصناعية. 1-1

اســخدمت شـريحة من السـيلكون احادية التبلور ذو اتجاهية (111) نوع توصـيلية P مشـوبة بذرات البورون) وبمقاومة

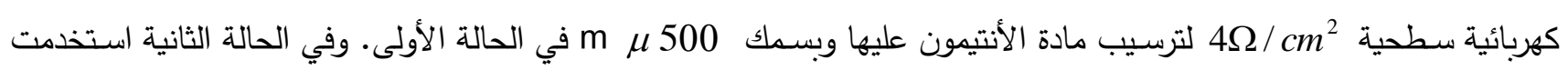
شريحة من السيكون ذات اتجاهية بلورية (111) نوع توصيلية N (مشوبة بذرات الفسفور ) وبنفس السمك وبمقاومة كهربائية سطحية

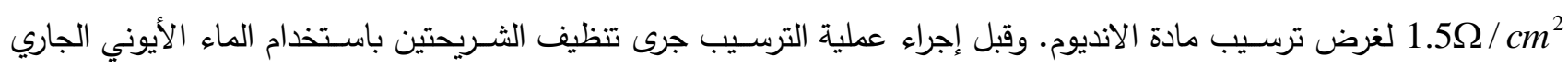
لمدة ثلاث دقائق وتشمل عملية التحضير ما يأتي: 1-5-1 تم تحضـير النماذج في مختبر كلية العلوم جامعة بغداد حيث تم اسـتخدام منظومة الطلاء الايوني وهي من التقنيات التي تجمع ما بين تقنية التبخير التقليدية والبلازما الغرض ترسـيب اغثـية رقيقة من الأنتيمون على شـرائح السـيلكون وبمعلمات فيزيائية تتصـف بالجودة إذا ما قورنت بتقنيات ترسـيب الأغثـية الرقيقة الأخرى ومن هذه المعلمات التماسـك العالي والتجانس وقلة الإجهاد الحراري. ووضـعت على القطب الكهربائي شـريحة الســيلكون ذات الجهد العالي السـالب وعلى بعد cm 10 من مصــدر التبخير وأجريت عملية المعالجة في بلازما الاركون وبضــغط 2×10 mbar ولفترة زمنية كافية لترسـيب مادة الأنتيمون واعيدت التجربة بتغيير زمن التبخير وتتثيت العوامل الأخرى للحصـول على أغشـية رقيقة من الانديوم بسـك 600A على شـرائح من السيلكون نوع توصيلية N. 
وبعد الانتهاء من تحضسير الأغشية الرقيقة جرى تتظيف النماذج بمحلول من حامض الهيدروفلوريك HF بتركيز 10\% ثم بماء ايوني جاري ولمدة خمس دقائق للتخلص من طبقة الأوكســيد المتكونة أثناء عملية نقل العينة إلى المنظومة ووضــــت داخل حاوية مغرغة من الهواء. 2-5-1

تم فحص النماذج المطلوبة باستخدام جهاز المجسات الأربعة Four point probe المعرفة نوع التوصيلية لهذه النماذج. وقد لوحظ بأن توصيلية شرائح السيلكون المطلاة بمادة الأنتيمون ما تزال من نوع توصيلية P وكذا الحال بالنسبة للشرائح المطلاة بمادة الانديوم حيث يثير القياس إلى أن الثريحة لا زالت من نوع توصيلية N ولكلا جهتي الشريحة.

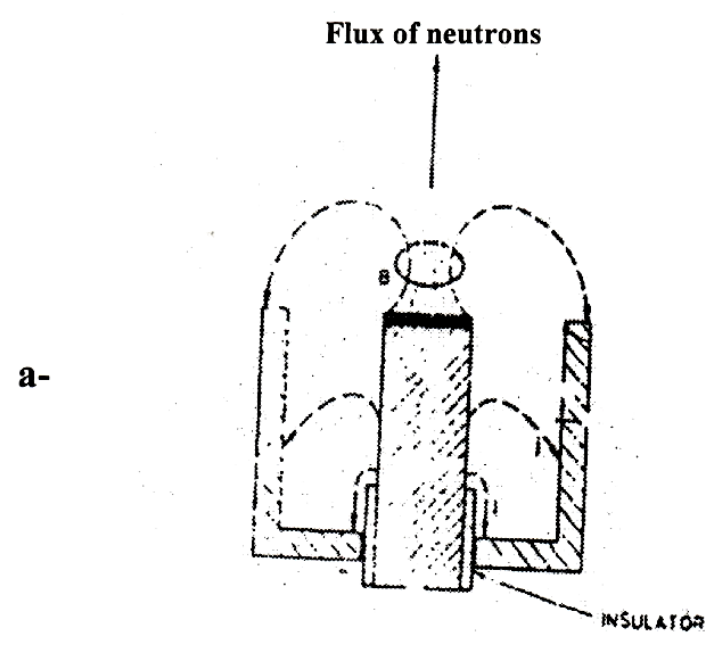

b-

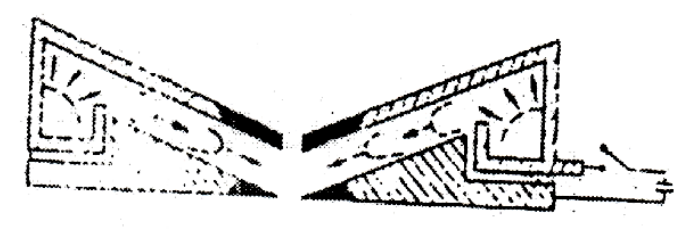

شكل (1): منظومة بئرة البلازما الكثيفة

:Dense Plasma Focusing(DPF)

Mather نو - a

Fillippov نو - b 


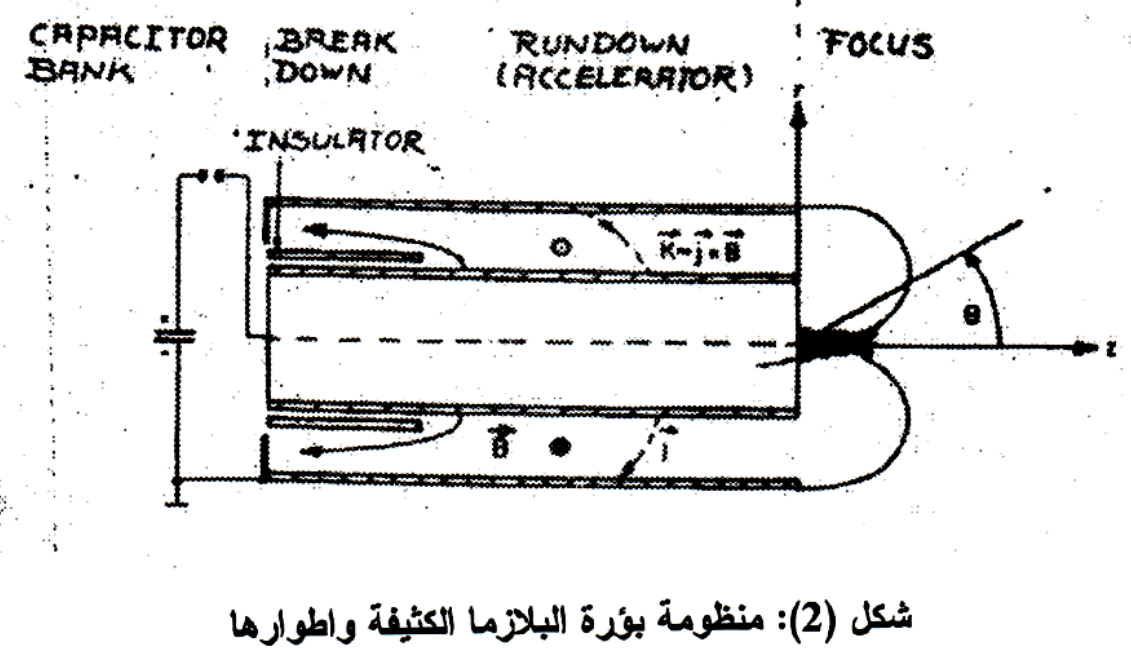




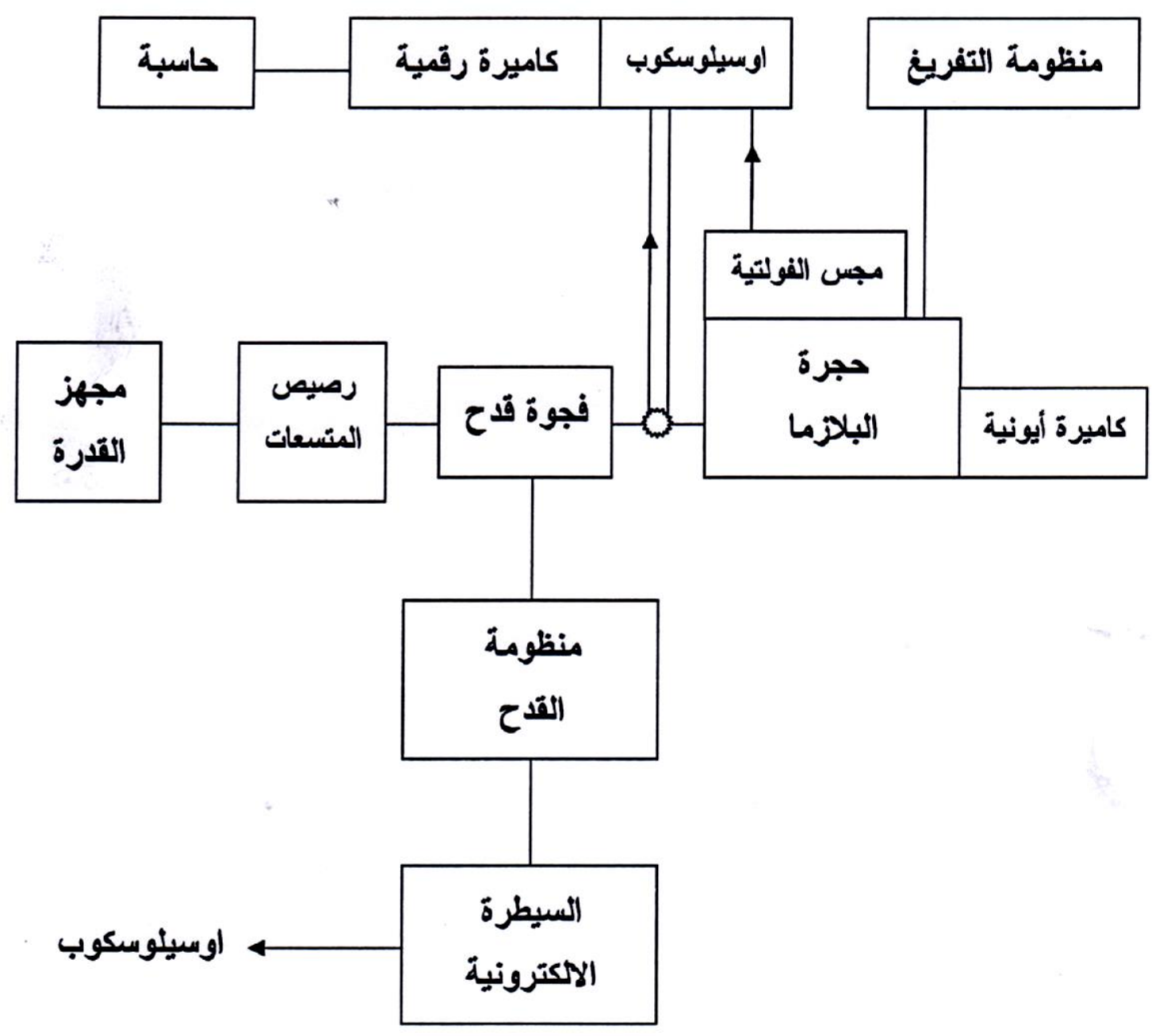

شكل (3): رسم تغطيطي لمكونات حاقن البلازما النبضي 


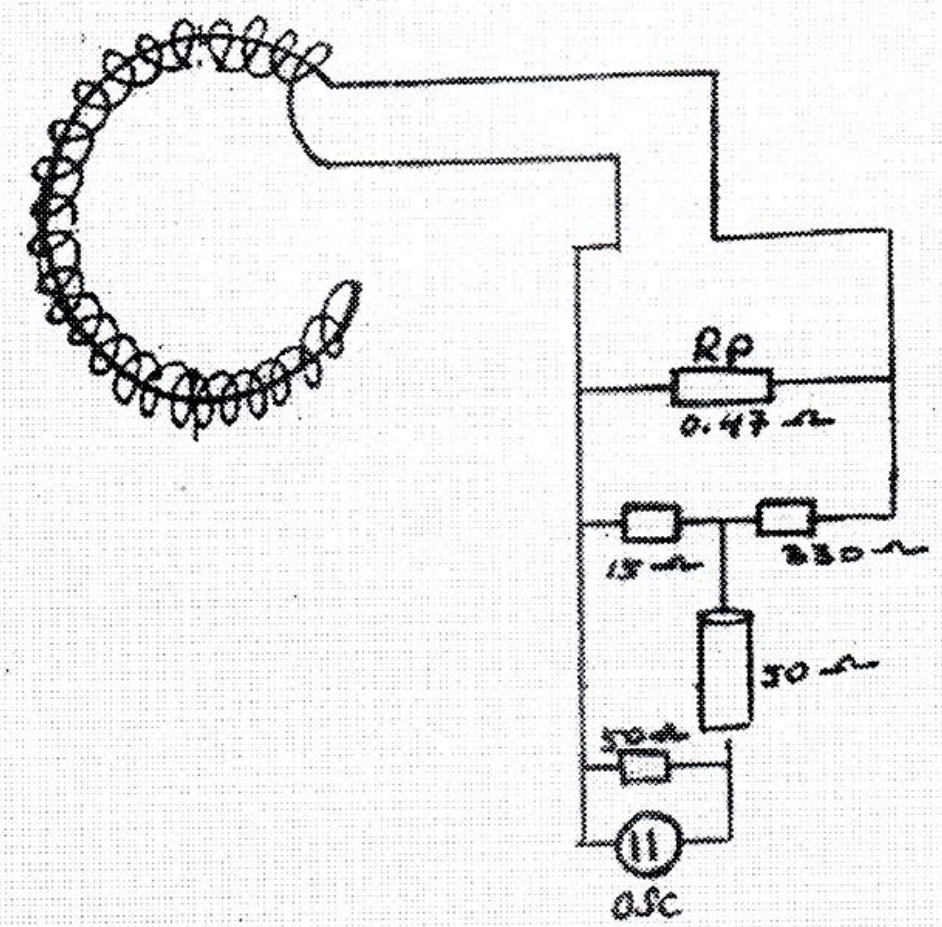

شكل (4): ملف راكوفسكي لقياس التيار

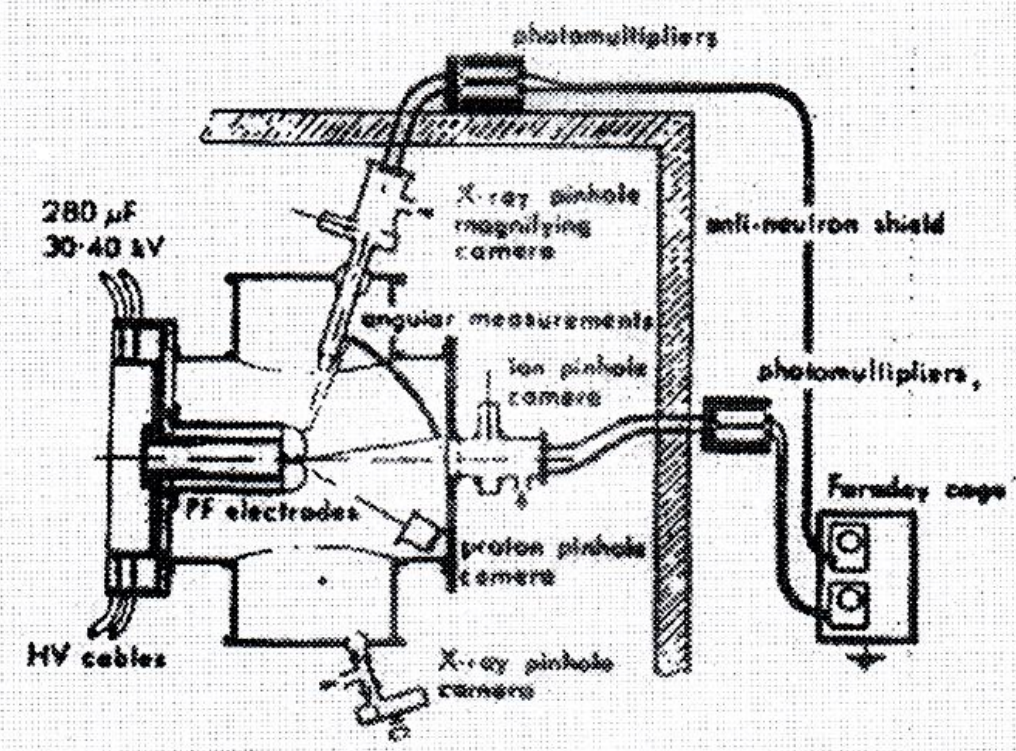

شكل (5): ترتيب أجهزة التشخيص لمنظومة بؤرة البلازما الكثيفة 
2-

P - N Junction detector properties 1-2 خصائص كاشف ثنائي الوصلة

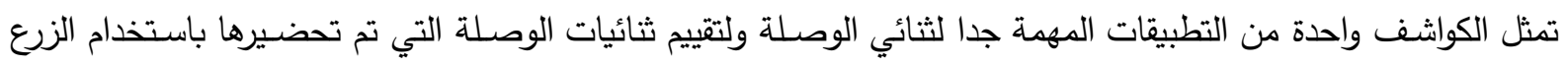

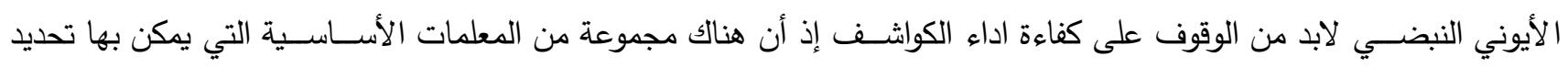

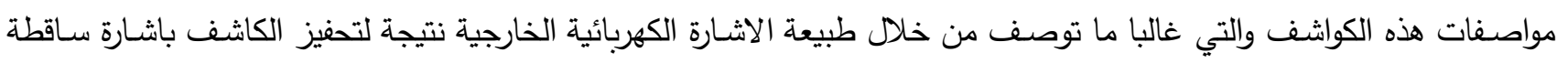
عليه.

:Responsivity 2-1-2 وتمثل نســبة الكمية الخارجة من الكاثــف إلى الكمية الداخلة وتقاس بوحدات أمبير / واط) أو (فولت/واط) ومن الوحدات

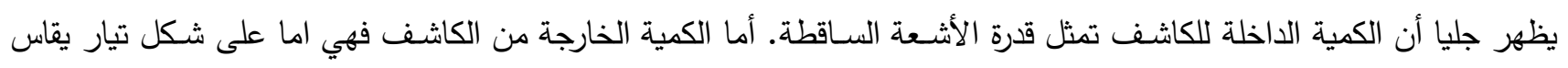

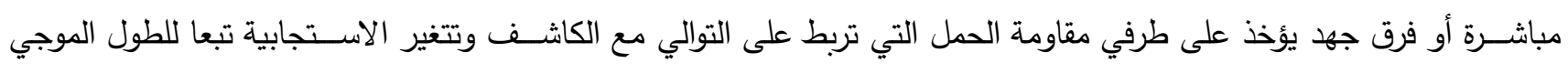

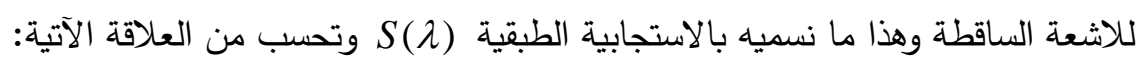
$S(\lambda)=I_{p h} P_{o}=\eta q \lambda / h c$

يمثل تيار الضوء، Iph

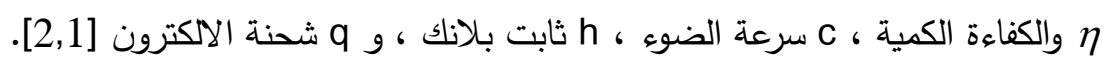
:Detectivity 3-1-2 تبرز اعلومة التحســــية كاعلومة مهمة لخواص الكاشـف والتي تمثل أقل قدرة يمكن للكاشـف تحسـسـها وتعطى بالعلاقة الآتية: $D=\frac{1}{N E P}$

$$
N E P=\left(I_{n} / I_{p h}\right) P_{o}
$$

NEP هي القدرة المكافئة للضوضاء وتحسب من العلاقة الآتية: $D=\left(I_{p h} / I_{n}\right) P_{o}$

In تمثل تيار الضوء وبالتعويض بالمعادلة In In تيار الضوضاء

$$
\begin{aligned}
& \text { ولأجل المقارنة بين الكواشف يصار إلى استخدام التحسية النوعية D* والتي تمثل التحسية لوحدة المساحة }
\end{aligned}
$$

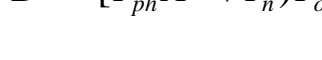

A

:Quantum efficiency الكفاءة الكمية، 4-2-1-2 تمثل الكفاءة الكمية لكاشف النسبة بين استجابية الكاشف إلى الفيض الكلي للأشعة الساقطة و يمكن تمثيلها ولطول موجي $\eta(\lambda)=\frac{I_{p h}}{P_{o} \lambda} \frac{h c}{q}$. معين بالعلاقة الآتية: - معتل 


\section{1-3 نتائج ومناقشة الاستجابية الطيفية:}

تم قياس الاستجابية الطيفية باستخدام منظومة فحص الكواشف DSR-500 والمبينة في الثكل (6) (6).

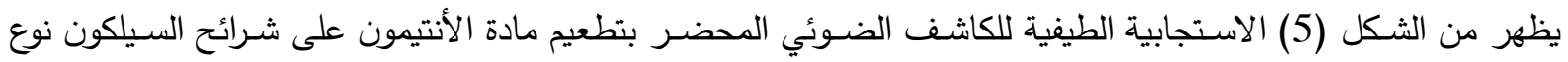

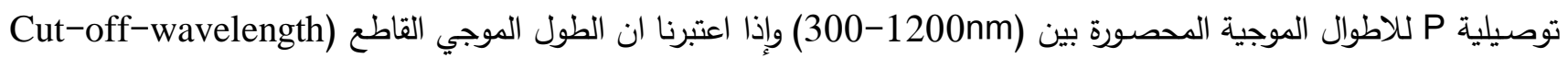
) هو الطول الموجي الذي تهبط فيه قيمة الاستجابية إلى 10\% من قيمة الاستجابية القصسوى Max Responsivity عليه يمكن

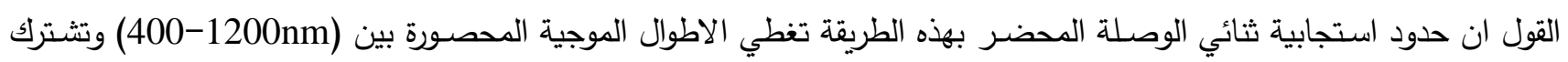

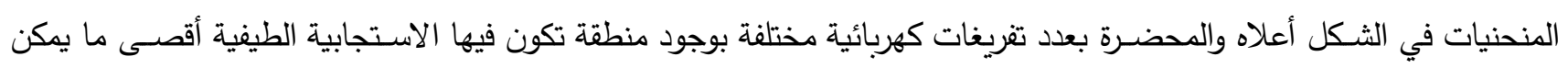

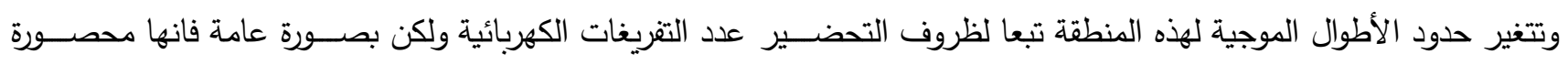
للاطوال الموجية المحصورة بين (1000nm-900). ويلاحظ أن قيمة الاستجابية الطيفية ولجميع الكواشف للاطوال الموجية المحصورة بين (1100nm-700) تزداد إلى ثلاثة

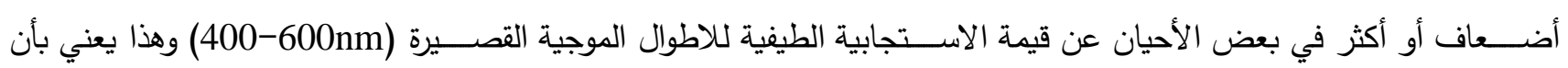
الكاشف ذو استجابية عالية للاطوال الموجية القرببة من المنطقة تحت الحمراء منها إلى المنطقة المرئية والفوق البنفسجية. اما الثكل (8) فيبين الاستجابية الطيفية للكواشف المحضرة بترسيب الانديوم على شريحة السيلكون ذات توصيلية نوع N.

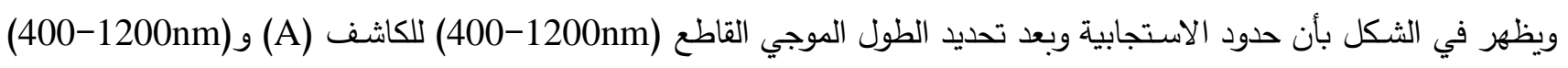
للكاشف (B) ومن (1200nm- (B50) للكاشف (C) كما موضح في الشكلين (6,5) وهذا يعني بان مدى الكثف يقل مع زيادة عدد

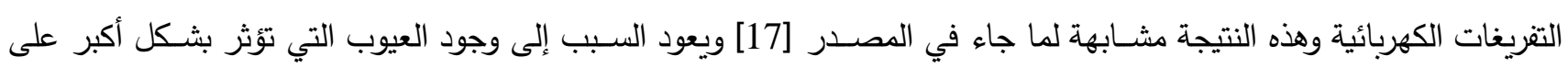
الاطوال الموجية القصيرة.

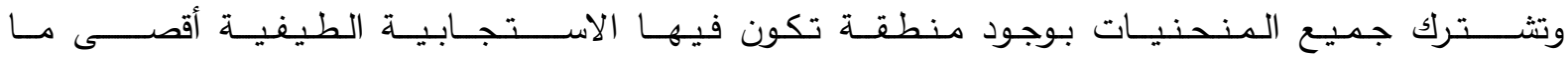
يمكن [29] وتتغير قيمة الاستجابية القصسى لعدد التقريغات (عدد النبضـات الأيونية) ولكنها تشترك بكون مداها محصسور للاطوال الموجية (1150nm-1000) وبقيمة استجابية أعلى من الكواشف المحضرة في الشكل (7) وهذا يعود إلى أن تركيز الثوائب لمادة الانديوم أعلى منه في حالة الأنتيمون لان الثريحة من نوع N ولكلا جنتي الثريحة. 


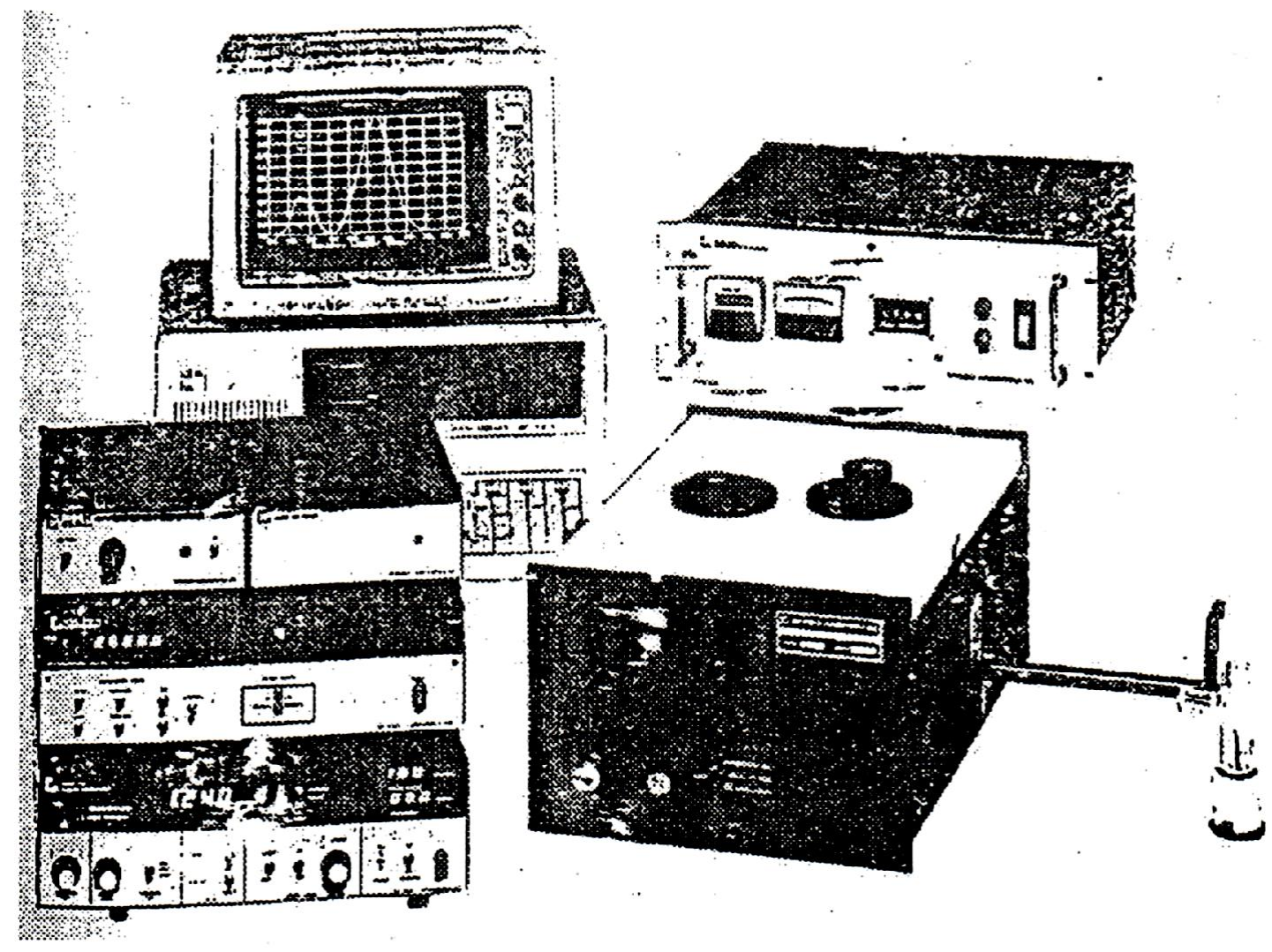

الشكل (6): منظومة فحص الكواشف DSR-500 

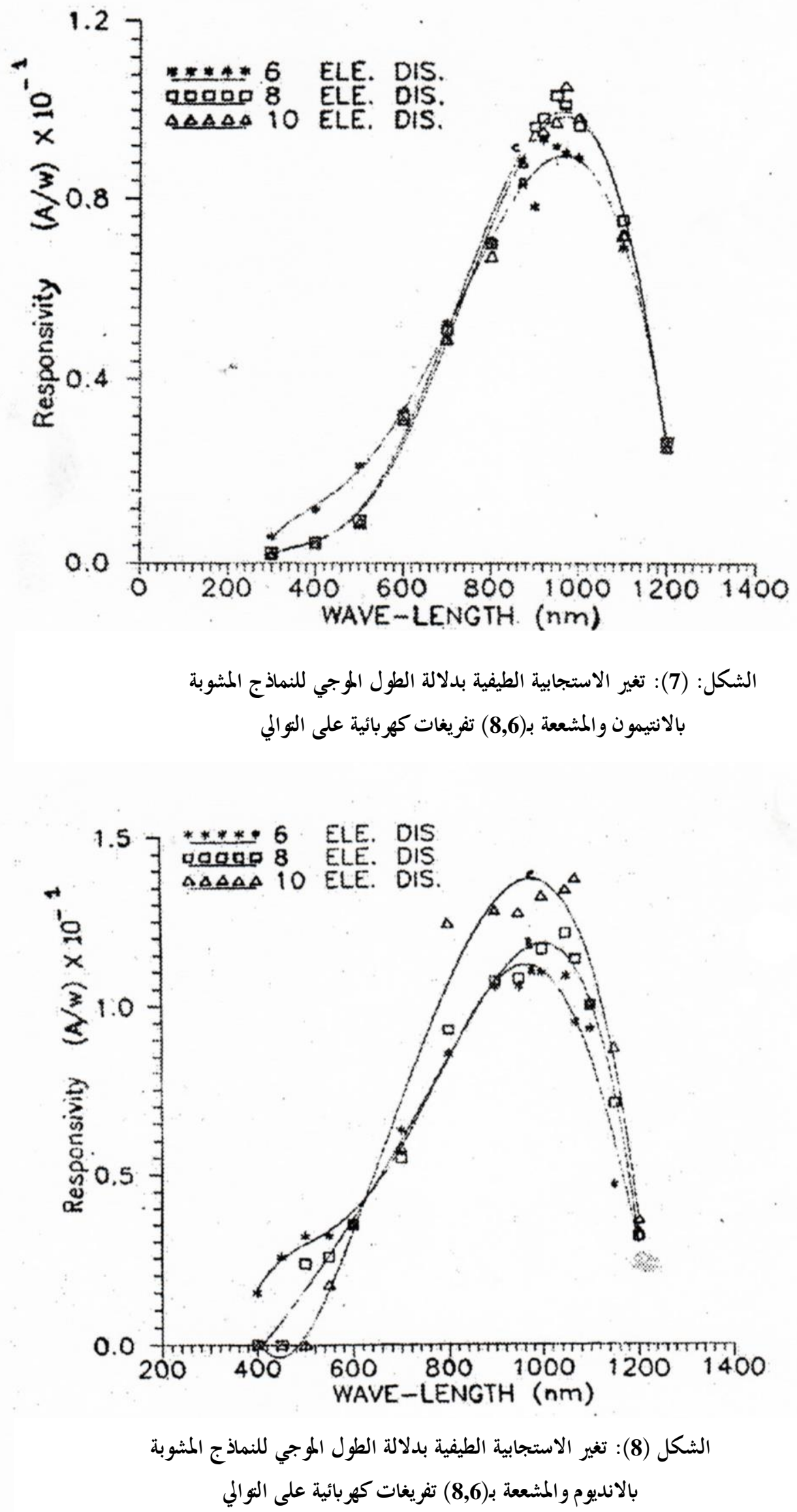
ويلاحظ أيضـا بأن قيمة الاستجابية الطيفية للاطوال الموجية القريبة من الأثـعة تحت الحمراء أكبر منها للاطوال الموجية للضوء المرئي وللاطوال الموجية للاشعة فوق البنفجية ولجميع الكواثف وان أعلى استجابية للكواشف تتحرف باتجاه المنطقة تحت الته الحمراء القريبة مع زيادة عدد التفريغات الكهربائية وهذه المواصفات تتكرر في الثكل (7) وتعتبر من المواصفات المهمة لهذا النوع من الكواشف المحضرة.

Quantum efficiency results 2-3-3 نتائج ومناقشة الكفاءة الكمية. الثكل (9) يوضح توزيع الكفاءة الكمية بالنسبة المئوية للكواشف المحضرة بعدد مختلف من التفريغات الكهربائية (النبضات الأيونية) ويظهر السلوك العام للكواشف متثابه من حيث التوزيع وكما هو الحال في الاستجابية الطيفية ويلاحظ وجود تباعد في قيم

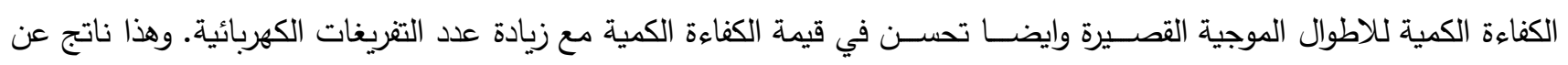

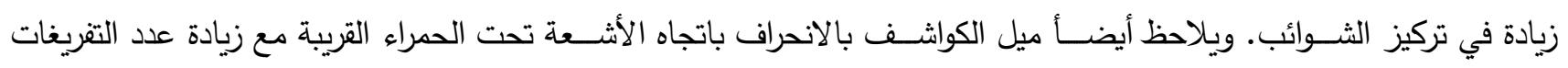

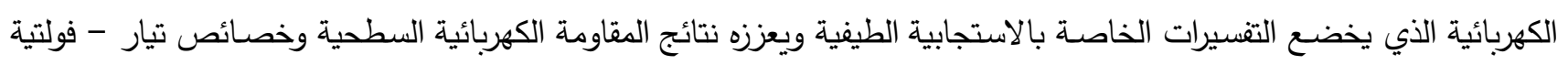

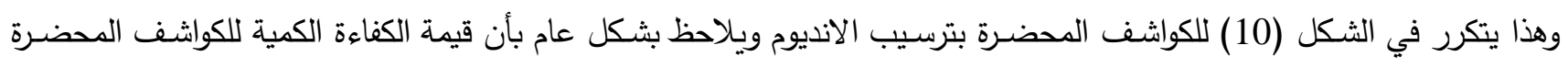

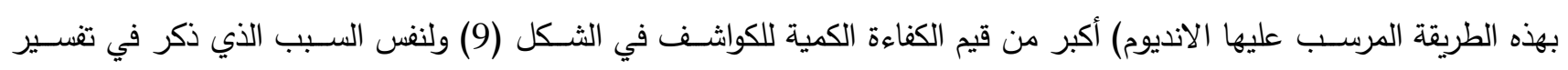

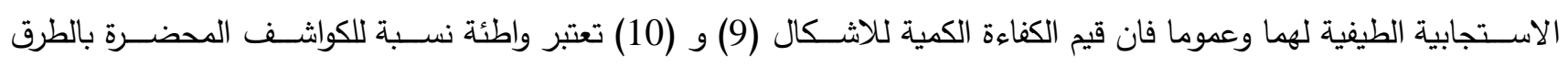
الكلاسـيكية وهذا يعود إلى عدة عوامل منها العيوب التي ترافق عملية التحضـير وكذلك الثــوائب الناتجة من عملية التفريخ (المواد المتطايرة) والطلاء الأيوني. 3-1-3 نتائج ومناقشة التحسية النوعية وزمن الاستجابة:

\section{Detectivity and Time Response Results:}

الاشكال (11) و (12) يمثلان قيم التحسسية وتغيرها مع الاطوال الموجية ويلاحظ أن سلوك التغير الحالتين متثـابه مع

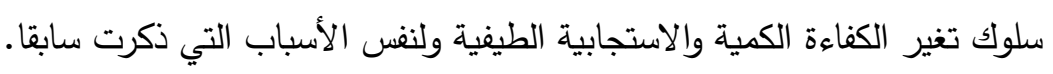

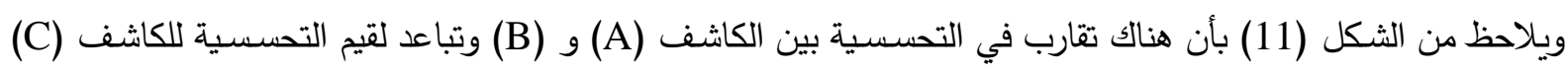
بالرغم من زيادة التحسية مع زيادة عدد التفريغات الكهربائية وكما ورد سابقا في الاستجابية الطيفية. 

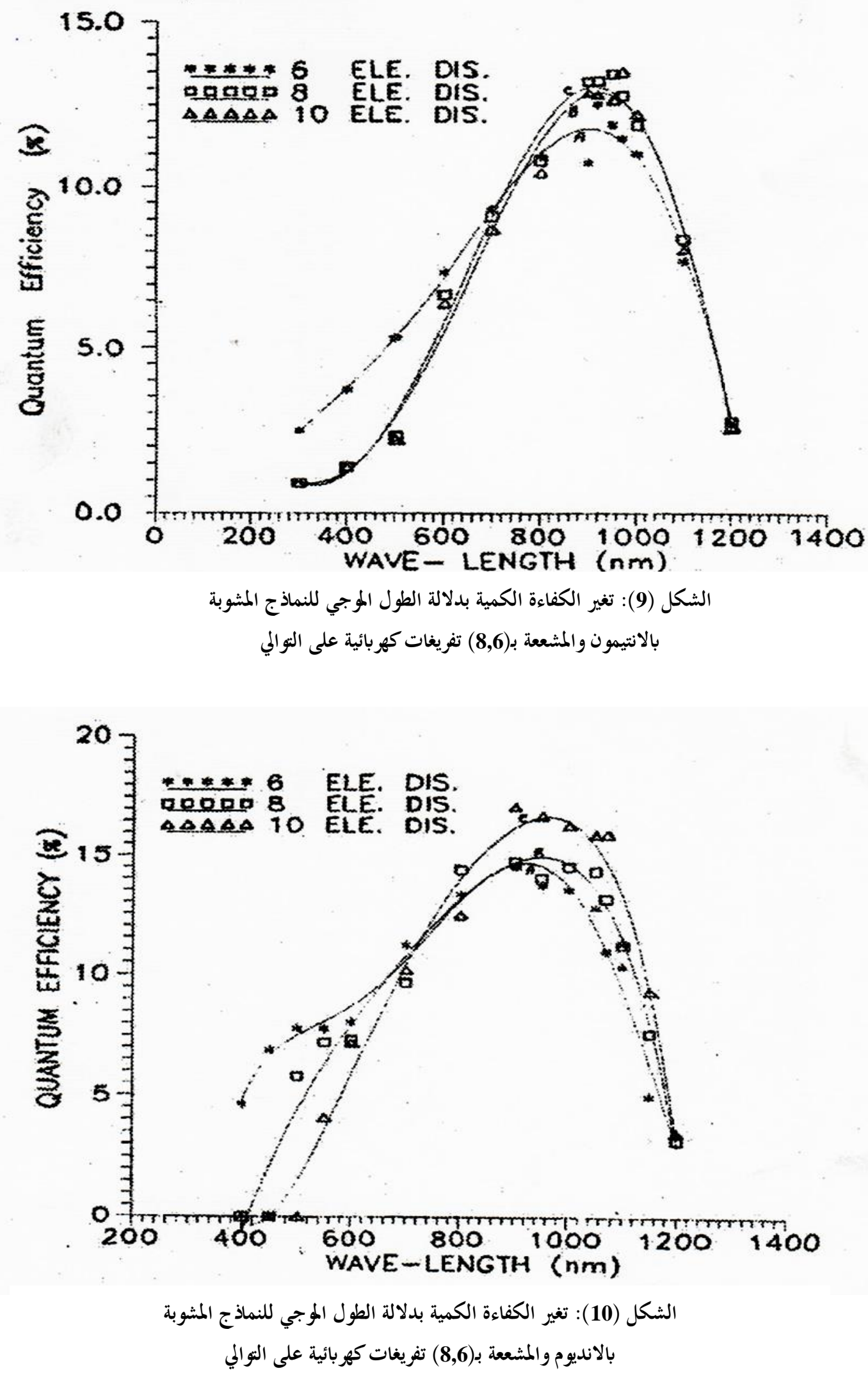


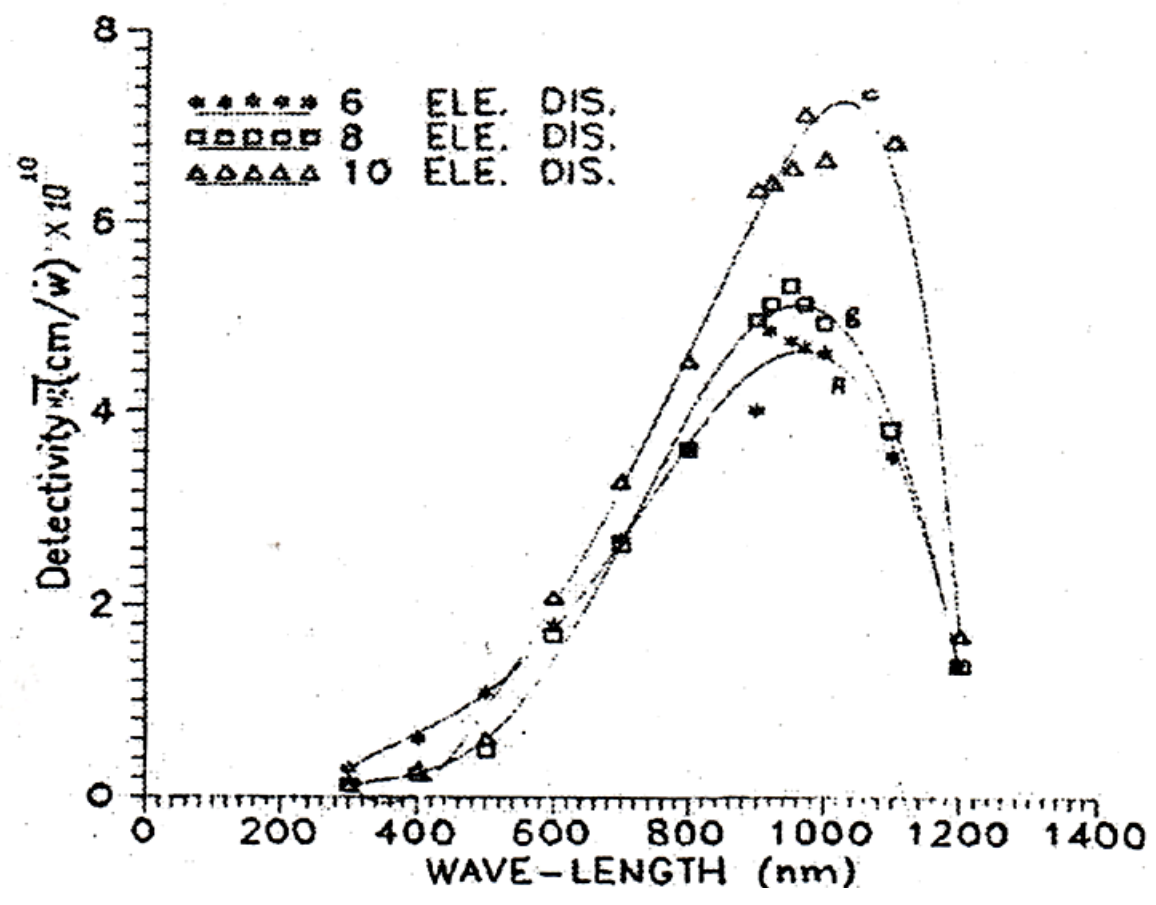

$$
\text { الشكل (11): تغير التحسسية بدلالة الطول الموجي للنماذج المشوبة }
$$

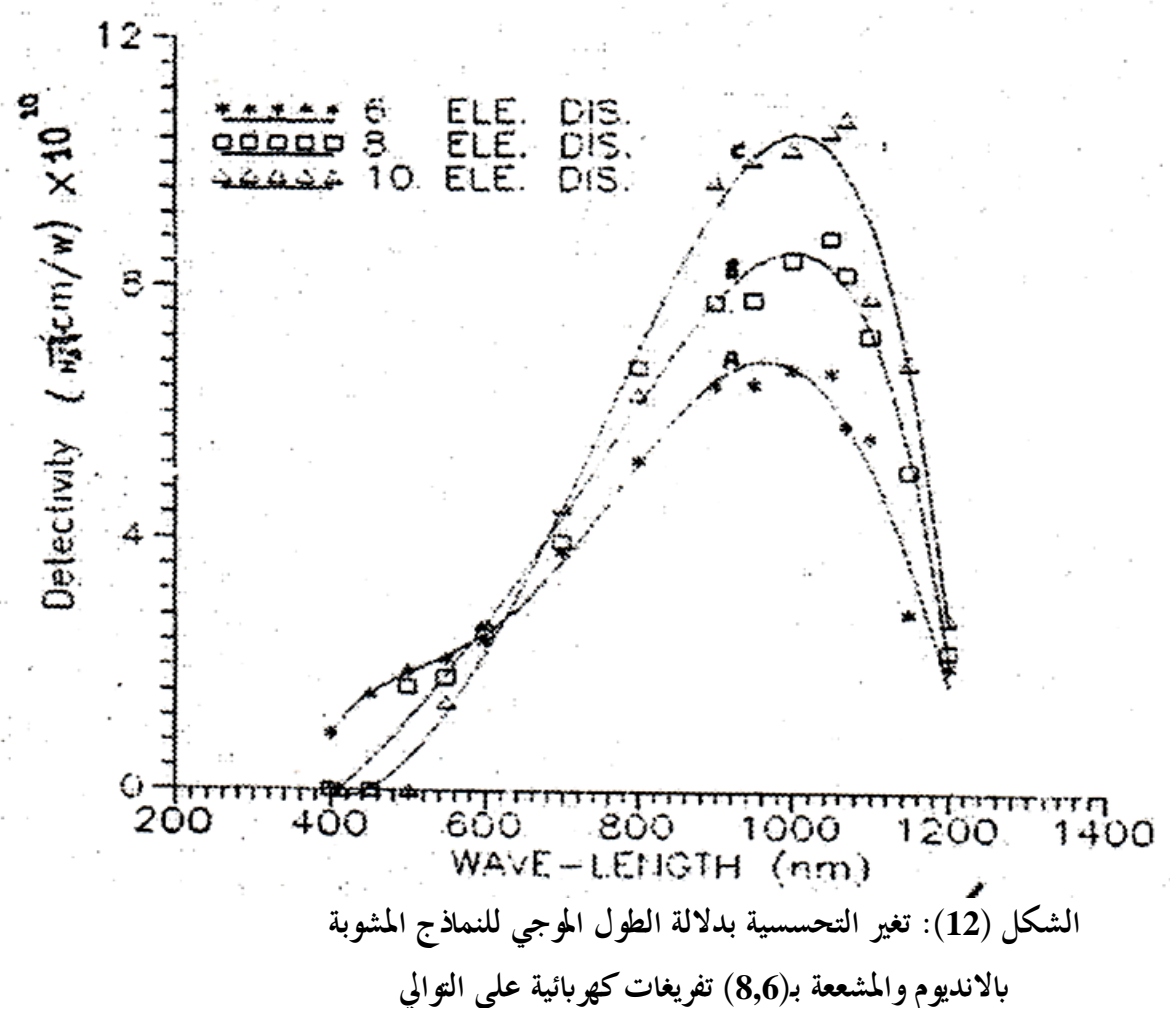




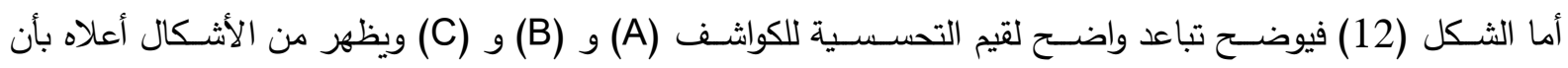

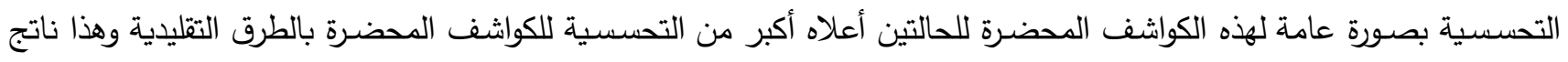

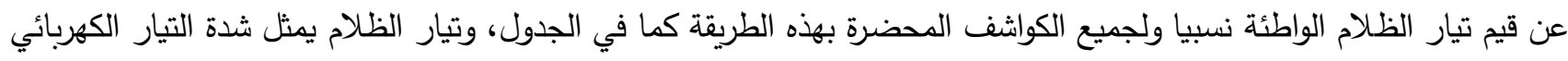

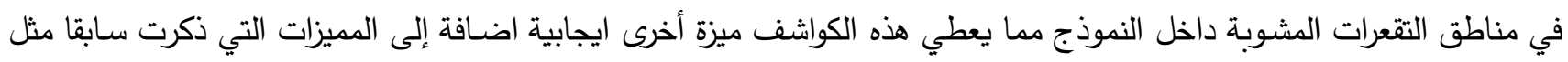

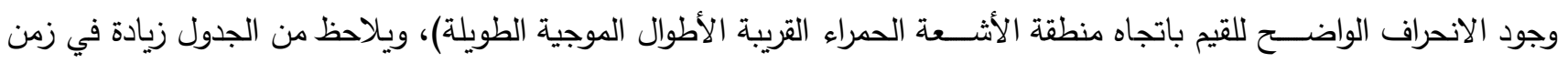

استجابة الكاشف مع عدد التثريغات الكهربائية.

الجدول رقم (1): يمثل قيم تيار الظلام وزمن استجابية الكواشف المحضرة

\begin{tabular}{|c|c|c|c|}
\hline مادة التطعيم & عدد التفريغات & زمن استجابة الكاشف & $\begin{array}{l}\text { تيار الظلاج } \\
\text { (ampere) }\end{array}$ \\
\hline \multirow{3}{*}{$\mathrm{Sb}$} & 6 & 120 & $8 \times 10^{-8}$ \\
\hline & 8 & 133 & $7.2 \times 10^{-8}$ \\
\hline & 10 & 170 & $5.8 \times 10^{-8}$ \\
\hline \multirow{3}{*}{ In } & 6 & 125 & $6.5 \times 10^{-8}$ \\
\hline & 8 & 138 & $6.1 \times 10^{-8}$ \\
\hline & 10 & 180 & $5.2 \times 10^{-8}$ \\
\hline
\end{tabular}

الاستنتاجات

1- لوحظت زيادة في قيمة الاسـتجابية الطيفية والكفاءة الكمية للاطوال الموجية الطويلة منطقة الأثـعة تحت الحمراء القريبة) عنها

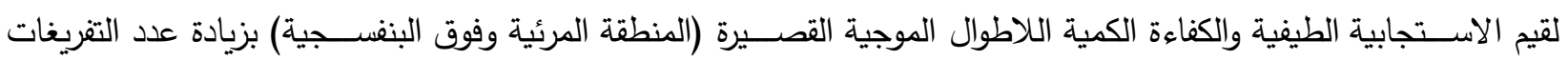
الكهربائية.

2- تعاني الكواشـف المحضـرة بهذه الطريقة من اسـتجابية طيفية وكفاءة كمية قليلة نسـبيا مقارنة مع الكواشـف المحضـرة بالطرق التقليدية ويعزى السـبب إلى العيوب التركيبية وعدم تجانس السـطح (وجود مناطق ارتفاع وانخفاض) مما يتسـبب في اسـتطارة

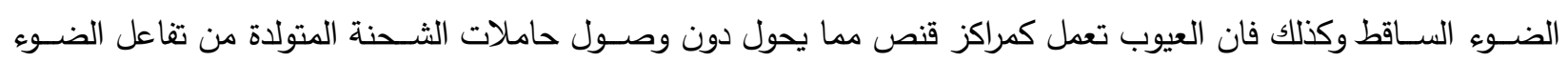
الساقط مع مادة الكاشف وكذلك يعزى إلى الشوائب غير المرغوب فيها (النحاس والاوكسجين والكاربون).

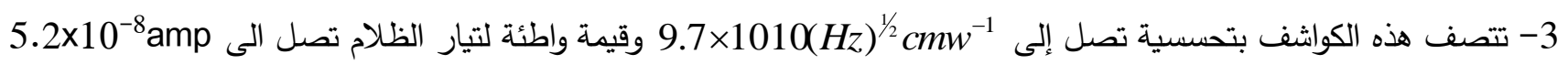

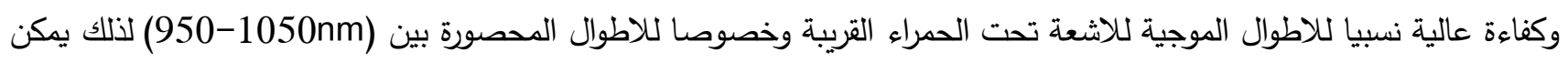

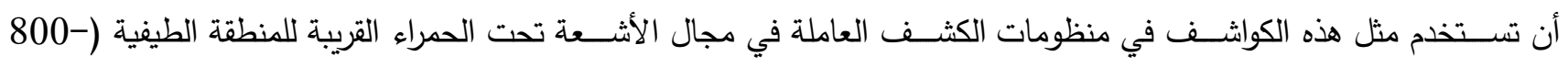

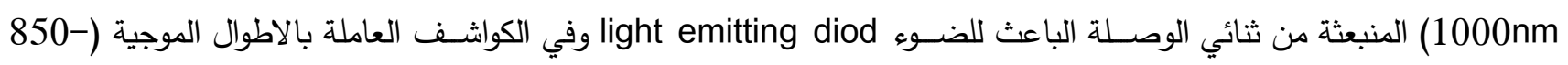
(950nm ومنها مفاتيح الأثـــــة تحت الحمراء الفعالة (Active infrared switches) وقارئ البطاقات ومنظومات التحذير الليزرية. 
1. J.W. Mather, "Methods or Experimental Physics", Vol.9, Academic Press, N. Y., 1971.

2. J.W. Mather, 4th Conf. On Plasma Physics and Nuclear Fusion, Wisconsin, 1971.

3. M. Trunk, "Numerical Parameter Studies for Plasma Focus", Institute of Plasma Research, University of Stuttgart, IPF 37-2, 1973.

4. Nuclear Focus Special Supply, B.I.10, P201, 1986.

5. T.Y. Tou, K.H. Kwek, Y.C. Yonged and S. Lee, "A Small Plasma Focus Device for Neutron, X-ray and Electron Beam Studies", Malya University, 1987.

6. M. Zabullah, J. J. Baig and G. Murtaza, "Numerical Design of Plasma Focus Optimization", Dept. of Physics, Quaid-i-Azam University Islamabad, Pakistan, 1987.

7. U. A. Suryadi, "Design of BATAN Plasma Focus Facility", Plasma Physics Lab. PPBMI, Indonisia, 1987.

8. A. Bernard, 3rd Topical Conf. on Pulsed High Beta Plasma, Culham. Pergamon Press, Oxford, 1976.

9. S. Lee, T. H. Ton. 7th European Conf. on Controlled Fusion and Plasma Physics, Proc. P. 65, 1975.

10. H. Schmidt, B. Nahrath, B. Ruckle, 7th European Conf. on Controlled Fusion and Plasma Physics, P. 57, 1976.

11. H. Herold, "Progress in Plasma Focus Operation Up to 500 KJ Bank Energy", Stuttgart, F.R.G., 1976.

12. 14. K.H. Kwek, T. Y. Tou. Y. C. Yong, J. Ali and S. Lee, "Numerical Design of UNUICTP Plasma Focus", Plasma Research Lab., Phys. Dept. 54100 Malaya Univ., 1986.

13. 15. S. H. Saw, C. S. Wong and S. Lee, "Design of Z Pinch for Current Sleeping Experiments", Malysia, 1986.

14. A. Zakulloh, S. A. Rizvi, F. N. Poigod and S. Bege, "Design of a small Plasma Focus Facilities", Dept. of Phys. Quaid-i-Azam Pakistan, 1986.

15. M.H. Eissa, A. Zabullahans, S. Lee, "Circuit Effect on the Operation Plasma Focus Device", 59100 Kulalampore, Malysia, 1987.

16. A. J. Smith, A. V. Chlop and K. H. Kwek, "Plasma Focus Operation in Difference Gases", Physics, Dept. Malysia, 1987. 
17. Z. Werner, J. Pickoszewski, C. Pochrybnrich, "Multiple Palse Implantation Dopped Layer in Silicon", Physical Research EPU 87, Poland, 1985.

18. E. Simon, L. Vanhellemont, C Claeys, A. Kaniavs and E. Gaubas, The Response of Si p-n junction diodes to proton irradiation, Semicond. Sci. Technol., 11 (1996) 1434-1442.

19. S. Chatrchyan, V. Khachatryan, A.M. Sirunyan, A. Tumasyan, W. Adam, E. Aguilo, T. Bergauer, M. Dragicevic, J. Erö, C. Fabjan, et al. Observation of a new boson at a mass of 125 $\mathrm{GeV}$ with the CMS experiment at the LHC. Physics Letters B, 716(1):30-61, 2012.

20. G. Aad, T. Abajyan, B. Abbott, J. Abdallah, S.A. Khalek, A.A. Abdelalim, O. Abdinov, R. Aben, B. Abi, M. Abolins, et al. Observation of a new particle in the search for the Standard Model Higgs boson with the ATLAS detector at the LHC. Physics Letters B, 716(1):1-29, 2012.

21. Compact Muon Solenoid (CMS). http://cms.cern/.

22. O. Brüning M. Lamont L. Rossi G. Apollinari, I. Bejar Alonso. Prelimary Design Report: HighLuminosity Large Hadron Collider. Technical report, CERN-2015-005, Geneva, 2015.

23. G. Apollinari, O. Brüning, T. Nakamoto, and L. Rossi. High Luminosity Large Hadron Collider HL-LHC. arXiv preprint arXiv:1705.08830, 2017

24. K. Klein. The Phase-2 Upgrade of the CMS Tracker. Technical report, 2017.

25. E. Currás, M. Fernández, C. Gallrapp, L. Gray, M. Mannelli, P. Meridiani, M. Moll, S. Nourbakhsh, C. Scharf, P. Silva, et al. Radiation hardness and precision timing study of silicon detectors for the CMS High Granularity Calorimeter (HGC). Nuclear Instruments and Methods in Physics Research Section A: Accelerators, Spectrometers, Detectors and Associated Equipment, 845:60-63, 2017.

26. N. Akchurin, V. Ciriolo, E. Currás, J. Damgov, M. Fernández, C. Gallrapp, L. Gray, A. Junkes, M. Mannelli, K.H. Martin Kwok, et al. On the timing performance of thin planar silicon sensors. Nuclear Instruments and Methods in Physics Research Section A: Accelerators, Spectrometers, Detectors and Associated Equipment, 859:31-36, 2017.

27. T. Quast. Construction and beam-tests of silicon-tungsten prototype modules for the CMS High Granularity Calorimeter for HL-LHC. arXiv preprint arXiv:1712.05638, 2017.

28. J. Butler, M. Klute, L. Silvestris, J. Mans, D. Contardo, et al. CMS Phase II upgrade scope document. Technical report, 2015

29. B. L. Wall, etal, Dead layer on silicon p-i-n diode charge-particle detectors, Center for Experimental Nuclear Physics and Astrophysics, and Department of Physics, University of Washington, Seattle, WA, USA, Oct., 2013, (1-13). 
30. Nikolina Vicoroski, Anthony Espinoza, and Mitchell Duncan, Development of a silicon diode detector for skin dosimetry in radiotherapy, Centre for Medical Radiation Physics, University of Wollongong, Wollongong, NSW 2500, Australia, Med. Phys, 44(10) Oct., 2017, (54025411).

31. H. Keivan, D. Shahbazi-Gahrouei, A. Shanei, Evaluation of dosimetric characteristics of diodes and ionization chambers in small megavoltage photon field dosimetry, International Journal of Radiation Research, July 2018, Volume 16, No.3, 2018, (311-321). 